\title{
The prevalence of gastrointestinal nematode infection and their impact on cattle in Nakuru and Mukurweini districts of Kenya
}

\author{
W. M. Kabaka ${ }^{a}$, G. K. Gitau ${ }^{b}$, P. M. Kitala ${ }^{a}$, N. Maingi ${ }^{c}$ and J.A. VanLeeuwen ${ }^{d}$ \\ ${ }^{a}$ Department of Public Health, Pharmacology and Toxicology, Faculty of Veterinary Medicine, \\ University of Nairobi \\ ${ }^{b}$ Department of Clinical Studies, Faculty of Veterinary Medicine, University of Nairobi \\ ${ }^{c}$ Department of Veterinary Pathology, Microbiology and Pathology, Faculty of Veterinary \\ Medicine, University of Nairobi \\ ${ }^{d}$ Centre for Veterinary Epidemiologic Research, Department of Health Management, Atlantic \\ Veterinary College, University of Prince Edward Island, Canada \\ *Corresponding author e-mail: wkabaka@gmail.com. Cell phone: +254726700700 .
}

\section{Abstract}

A cross-sectional study was conducted in Nakuru and Mukurweini districts of Kenya to estimate the prevalence of gastrointestinal nematodes (GIN) and the financial impact of such infections among smallholder dairy farms. Parasitological examination involving feacal egg count and larval culture was employed to determine prevalence and burden of GIN. Questionnaires were administered to collect individual animal and farm management data. The impact of GIN infection on average daily milk production in lactating cows was also estimated using generalized linear regression analysis The prevalence of GIN infection was significantly different $(p<0.05)$ between Nakuru and Mukurweini, at $19.8 \%$ and $8.3 \%$, respectively ( $13.8 \%$ overall), for a relative risk of infection of 2.3. Farm-level prevalence of infections were estimated at $28.1 \%(36 / 128)$ for Haemonchus, $19.5 \%$ (25/128) for Trichostrongylus and $14.8 \%(19 / 128)$ for Oesophagostomum. Average daily milk production in litres in the GIN-infected milking cows was 5.4 compared to 7.8 in the noninfected cows. GIN infection was associated with 1.4 litres per cow per day less milk and this difference was statistically significant $(\mathrm{p}<0.05)$. The observed difference in milk production translated to a daily loss of 0.35 US dollars (USD) per cow per day at a cost of 0.25 USD per litre, which was the average farm gate price of milk at study time in the area under study.

Keywords: Cattle, Gastrointestinal nematode infections, Milk production, Cross-sectional study. http://dx.doi.org/10.4314/evj.v17i1.8 


\section{Introduction}

Gastrointestinal nematode (GIN) infections in cattle are of considerable economic importance, causing clinical disease and mortalities, but more importantly, by causing subclinical chronic production losses as a result of weight loss, reduced weight gain, and reduced milk production (Over et al., 1992).

GIN infections have been observed to affect younger cattle more than adults, with the super family Trichostrongyloidea having the biggest impact, leading to clinical manifestations including pale mucous membranes due to anemia, poor body condition (Urquhart et al., 1996), and reduced immunity (Charlier et al., 2009). In Africa, a study carried out in Ouagadougou, Burkina Faso, on the prevalence of GIN in cattle showed that Cooperia was most prevalent $(89.4 \%$ ), followed by Haemonchus contortus (66\%), and Oesophagostomum radiatum (42.6\%), whereas Haemonchus became predominant in the rainy season as it was able to withstand harsh climatic condition through arrested development in the L4 stage (Belem et al., 2001). In Kenya, infestation with GIN in dairy cattle was common (Maingi et al., 1998). A study carried out on cattle in Central Kenya showed that Haemonchus, Trichostrongylus, Cooperia and Oesophagostomum were responsible for parasitic gastroenteritis, Haemonchus placei being the predominant nematode (Waruiru et al., 2001). A study done in Zimbambwe on 16,264 communally grazed cattle, by Pfukenyi et al., (2007), showed the prevalence of GIN to be $43 \%$. Another study carried out in Ngorongoro District of Tanzania on pastoral cattle found the prevalence of GIN to be $20 \%$ (Swai et al., 2006).

The milk yield after anthelmintic treatment on pastured dairy cattle in the Netherlands was estimated to increase by $1 \mathrm{~kg} / \mathrm{cow} / \mathrm{day}$ (Charlier et al., 2009). There is limited information on the economic impacts of GIN on milk production in Africa. The objectives of this study were to estimate the prevalence of GIN infection and the financial impact of such infections among smallholder dairy farms.

\section{Materials and Methods}

Study area

The study was carried out in Mukurweini District of Nyeri County and Nakuru District of Nakuru County between June $16^{\text {th }} 2010$ and August $30^{\text {th }} 2010$. Nyeri County is one of the five counties of Central Province and forms part of Kenya's central highlands (The Constitution of Kenya, 2010). Dairy farming is an important 
enterprise in Mukurweini District, with the farmers practicing zero-grazing methods, where pastures are cut and carried to the cattle. Nakuru County is one of the 14 Counties of the Rift Valley Province and it lies within the Great Rift Valley (The Constitution of Kenya, 2010). Dairy farmers in the area practice both zero-grazing, and semi-zero-grazing, where the cattle are housed but allowed to graze at certain times.

\section{Study design}

A cross-sectional study was carried out on 419 heads of cattle that were on 128 farms (64 farms in each district), to establish the prevalence and economic impact of gastrointestinal nematode infections in Nakuru and Mukurweini districts of Kenya. In Nakuru, a simple random selection was employed at the farm level using a sampling frame of the dairy farms provided by the District Livestock Production Officer. For logistical reasons, a purposive sampling method was used in Mukurweini, as the research was conducted alongside another project comparing smallholder dairy farms with and without biogas digesters (Dohoo et al., 2012a; Dohoo et al., 2012b). In that study, biogas digesters were distributed to a group of smallholder dairy farmers considered representative of the various sub-districts and demographics of smallholder dairy farmers in the area, and the referent group of farmers was randomly selected. Due to the similarity of farming practices across smallholder dairy farms in the district (virtually all zero-grazing units), the Mukurweini sample of farms was considered a fair representation of the population in the district. In Mukurweini district, all cattle that were above three months of age on the selected farms were sampled for the study. In Nakuru district, some farms were larger, and therefore on farms that had more than 10 heads of cattle, a systematic random selection method was used to ensure that no more than 10 animals were sampled per farm.

\section{Data collection}

Faecal samples from each animal on the selected farms were collected and analyzed for faecal egg counts (FEC) using a Modified McMasters technique (Ministry of Agriculture, Fisheries and Food, 1986), with a lower detection limit of 50 eggs per gram (epg). Faecal samples from a farm were pooled and larval cultures were conducted on the pooled sample.

Questionnaires were administered to the participating farmers to collect individual animal and farm management data, such as age, parity, sex, breed, body condition score, and feeding management. Animal weight was estimated using a heart girth tape. 
Data regarding the stage of lactation of the milking cows and daily milk production were collected from the farmer for the purpose of estimating the milk production loss associated with GIN infection.

Data analyses

For comparison purposes of worm loads with other studies, the mean, 95\% confidence interval, and range of FECs (in epg) was calculated per district in both the immature cattle (3-12 months) and the adults (above 12 months), to examine the effect of age on the FECs (Georgi et al., 1997). A binary outcome was preferred to a continuous data outcome because: 1) the McMasters egg counting method gave an output in multiples of 50(each egg seen represented 50 eggs); and 2) the data had a right-skewed and a non-Gaussian distribution of the egg counts that could not be normalized with transformations. A threshold of $100 \mathrm{epg}$ and above was considered GIN infection positive, and below 100 as negative (Hansen, 1994). One egg seen (representing 50 egg) could be a false positive due to the passing through of ingested eggs, or a very light level of parasitism.

A computation was carried out to establish whether there was an association between the district and the infection status using the chi-square (Thrusfield, 2007). Prevalence of infections in the different age groups was computed and tabulated to compare the risk of gin infection between the calves ( $<12$ months) and the adults. Similarly the prevalence of gin infection by grazing management was tabulated, and a chi-square was calculated to compare the risk of gin infection in the zero-grazed and the free-range management systems.

Faecal samples from each farm were pooled and mixed, and the presence of each gin genus was determined following identification keys (Ministry of Agriculture, Fisheries and Food, 1986). the prevalence of each gin genus was calculated by taking the ratio of the farms infected with each genus to the total farms at risk of such infections.

To estimate the impact of gin infection on milk production, the mean and the $95 \%$ confidence interval of the milk yield in the milking cows, by gin status, was calculated. a generalized linear regression analysis was used to estimate the effect of gin infection on milk production, controlling for significant confounders, such as breed, animal weight, parity, lactation stage, cmt status and the amount of concentrates fed to the animals. 


\section{Results}

Mean faecal egg counts of gastrointestinal nematodes

The overall mean, 95\% confidence interval, fecs were 48.0, 35.2 to 60.8 in cattle less than 12 months of age, and 18.4, 12 to 24.8 in cattle more than 12 months of age, respectively. the mean egg counts were significantly higher $(p=0.05)$ in cattle less than 12 month compared to older cattle, in both districts(table 2).

Table 2. Mean faecal egg counts of gastrointestinal nematodes and the $95 \%$ confidence intervals for all the 419 cattle Sampled, by age group and district, between June $16^{\text {th }} 2010$ and August $30^{\text {th }} 2010$.

\begin{tabular}{lll}
\hline District & $\begin{array}{l}\text { 3 months to 12 months - } \\
\text { mean epg and 95\% CI }\end{array}$ & $\begin{array}{l}\text { Above 12 months - } \\
\text { mean epg and 95\% CI }\end{array}$ \\
\hline Nakuru & $62.8[58.2,67.4]$ & $29.6[17.8,41.4]$ \\
& $\mathrm{n}=43$ & $\mathrm{n}=159$ \\
Mukurweini & $36.4[26.2,46.6]$ & $7.4[2.7,12.1]$ \\
& $\mathrm{n}=55$ & $\mathrm{n}=162$ \\
Overall & $48.0[35.2,60.8]$ & $18.4[12.0,24.8]$ \\
& $\mathrm{n}=98$ & $\mathrm{n}=321$ \\
\hline
\end{tabular}

$95 \% \mathrm{CI}=95 \%$ confidence interval

\subsection{Gastrointestinal nematode species}

The pooled larval cultures showed that Haemonchus, Trichostrongylus, and Oesophagostomum were the most common gastrointestinal nematodes found in the animals. Overall farm level prevalence of infections were estimated at $28.1 \%$ (36/128) for Haemonchus, 19.5\% (25/128) for Trichostrongylus, and 14.8\% (19/128) for Oesophagostomum.

In Nakuru District, Haemonchus was present in 33\% (21/64) of the farms, Trichostrongylus was found in $25 \%(16 / 64)$ of the farms, while Oesophagostomum was found in 19\% (12/64) of the farms. In Mukurweini District, Haemonchus was present in 23\% (15/64) of the farms, Trichostrongylus was found in $14 \%(9 / 64)$ of the farms, while Oesophagostomum was found in $11 \%(7 / 64)$ of the farms. 
Crude prevalence of gastrointestinal nematode infection

A 2 X 2 table was constructed to show the distribution of GIN infections in the Mukurweini and Nakuru districts (Table 3).

Table 3. Comparison of gastrointestinal nematode infection status in 419 cattle on 128 dairy farms per district between June $16^{\text {th }} 2010$ and August $30^{\text {th }} 2010$.

\begin{tabular}{llll}
\hline District & Infection +ve & Infection -ve & Total \\
\hline Nakuru & $40(19.8 \%)$ & 162 & 202 \\
Mukurweini & $18(8.3 \%)$ & 199 & 217 \\
Total & $\mathbf{5 8 ( 1 3 . 8 \% )}$ & $\mathbf{3 6 1}$ & $\mathbf{4 1 9}$ \\
\hline
\end{tabular}

There was a significant $\left(\chi^{2}=11.6, \mathrm{p}<0.05\right)$ difference in GIN prevalence between the two districts. The relative risk was 2.3 showing that the risk of the GIN infection was more than twice in Nakuru as compared to Mukurweini.

The prevalence of GIN infection in free range cattle was $20.7 \%,(22 / 106)$ compared to $11.5 \%(36 / 313)$ in the zero-grazed animals. The difference was significant $\left(\chi^{2}=5.7, p<0.05\right)$, Fifty-two percent $(106 / 202)$ of cattle in Nakuru were on free-range grazing, while all the cattle in Mukurweini were on zero-grazing farming systems.

The prevalence of GIN infection in animals less than 12 months of age was $21.9 \%$ $(32 / 146)$ and $9.5 \%(26 / 273)$ in animals more than 12 months old; the difference was statistically significant $\left(\chi^{2}=12.2, \mathrm{p}<0.05\right)$. An odds ratio of 2.7 showed that the odds of infection was more than two times in cattle less than 12 months compared to animals above 12 months of age. All the male animals sampled were calves less than 12 months of age, and there was no significant difference in prevalence of infection by gender.

Impact of gastrointestinal nematode infection on milk production

Mean milk production in the cows that showed no GIN infection $(n=170)$ was estimated at $7.8 \mathrm{Kg} / \mathrm{cow} /$ day with a $95 \%$ confidence interval of 4.16 to 6.77 , while mean milk production in the GIN-positive group $(\mathrm{n}=48)$ was $5.5 \mathrm{Kg} /$ cow/day with 
a $95 \%$ confidence interval of 6.93 to 8.61 . However, this difference of 2.3 $\mathrm{kg} / \mathrm{cow} /$ day did not control for the effects of other factors likely to affect milk production, such as cow breed, weight, parity, lactation stage, CMT, and the amount of concentrates fed.

A generalized linear regression analysis with milk production as the outcome and GIN status as an explanatory variable, controlling for the effect of cow breed, weight, parity, lactation stage, CMT, and the amount of concentrates fed to the animals, showed that GIN infection was associated with $1.4 \mathrm{~kg}$ per cow per day less milk $(\mathrm{p}<0.05)$.

\section{Discussion}

Our study showed that a prevalence of GIN infection, observed in Nakuru was significantly higher than the prevalence observed in Mukurweini. The relative risk indicated that the risk of GIN infection was more than twice as high in Nakuru compared to Mukurweini, and this difference was partially a function of the fact that over half of the cattle sampled in Nakuru district were free-ranging, which were more likely to be GIN infected than zero-grazed cattle. The overall prevalence of $13.8 \%$ estimated in this study was lower than that of $20 \%$ from a previous study by Swai et al. (2006), in Ngorongoro, in free-range pastoral cattle. The results also differed with another study carried out by Waruiru et al., (2001) in Kiambu District on Bos indicus and B. taurus crosses on free range pasture which showed a prevalence of $75.9 \%$ in adults and $87.6 \%$ in immature animals. The lower prevalence in our study may be attributed to the improved management practices in both districts, especially in Mukurweini district, where the dairy farmers use zero-grazing units and treat for GINs regularly. In the two districts under study, dairy production is the biggest economic activity and as a result, the farmers have appeared to step up management activities, such as housing, feeding and helminth control. This anecdotal improved management may have resulted in a reduction in GIT nematodes infections. Due to the large variation in cattle management practices from various districts in Kenya, it is likely that the results of this study are limited to districts with similar management practices and therefore cannot be extrapolated as estimates for the country. The prevalence deduced here may therefore tend to underestimate the true prevalence in the whole country.

The current study agrees with a previous study carried out in Kiambu District in Kenya, which demonstrated that nematode prevalence was higher in cattle less than 12 months of age (Waruiru et al., 2000). 
The pooled larval culture showed that Haemonchus, Trichostrongylus, and Oesophagostomum were the most common nematodes found on the farms, with Haemonchus being present in $28 \%$ of the farms followed by Trichostrongylus $(19.5 \%)$ and Oesophagostomum (12.5\%). Haemonchus was also the predominant species of GIN in a previous study that was carried out in Kiambu District by Waruiru et al., (1998) that showed the following prevalence: Haemonchus placei $(67.0 \%)$, Cooperia pectinata $(53.0 \%)$, and Cooperia punctata $(41.7 \%)$. It is unclear why Cooperia were not identified in our study.

The current study showed that GIN-infection was associated with 1.4 liters per cow per day less milk, after controlling for farm clustering and significant confounders. This agrees closely with a similar study carried out in the Netherlands that estimated the milk yield response after anthelmintic treatment of pastured dairy cattle to be $1 \mathrm{~kg} / \mathrm{cow} /$ day more milk (Charlier et al., 2009). As milk is the most important output in a dairy enterprise, GINs lead to direct loss in production and income. At the price of 0.25 USD (US Dollars) per liter, which was the average farm gate price of milk in the study area at that time, a loss of 0.35 USD per cow per day was attributable to nematode infection. With dewormers costing 2.5 to 5 USD per cow at the time of the study, anthelmintic treatment would likely to be a cost-beneficial management tool among infected cattle.

\section{Conclusion}

GIN infection was relatively common (14\%), with a higher prevalence observed in Nakuru District compared to Mukurweini District, and among calves as compared to adults. The most prevalent genus was Haemonchus. GIN infection was associated with $1.4 \mathrm{~kg}$ per cow per day less milk, costing Ksh 28/cow/day. To avoid such losses in production, efforts should be directed towards GIN control in groups of animals that are considered at higher risk of infection.

\section{Acknowledgement}

The study was sponsored by Farmers Helping Farmers, a Canadian non Governmental organization, the Atlantic Veterinary College, Veterinarians without Borders-Vétérinaires sans Frontières-Canada, and the XXIII World Veterinary Congress Foundation. Mr. R. Otieno and Miss. R. Githinji are hereby acknowledged for their contribution in processing the samples, and Ms. Laura Bourque and Vionna Kwan for assisting in sample and data collection 


\section{References}

Belem A. M. G., Ouedrago O. P., Bessin R. 2001. Gastro-intestinal nematodes and cestodes of cattle in Burkina Faso. Biotechnol. Agron. Soc. Environ. 5, 17-21.

Charlier J., Hoglund J., Samson-Himmelsjerna G., Dorny P., Vercruyss J. 2009. Gastointestinal nematode infection in adult dairy cattle: Impact on production, diagnosis and control. Vet. Parasitol. 164, 70-79.

Dohoo C., VanLeeuwen J.A., Guernsey J., Critchley K. 2012a. Impact of biogas digesters on wood utilization and self-reported back pain on rural Kenyan smallholder dairy farms. Global Pub. Health. In Press.

Dohoo C., Guernsey J., Critchley K., VanLeeuwen J.A. 2012b. Pilot study on the impacts of biogas digesters on respiratory health in women on Kenyan smallholder dairy farms. J. Environ. Public Health. In Press.

Dohoo, I. R., W. Martin, and H. Stryhn. (2009). Veterinary Epidemiologic Research. AVC Inc., Charlottetown, Prince Edward Island, Canada.

Georgi J. R., Georgi M. E. (1997). Parasitology for Veterinarians. $5^{\text {th }}$ edition W. B. Saunders Company. pp 138-223.

Hansen J., Perry B. (1994). The epidemiology, diagnosis and control of helminth parasite of ruminants. ILRAD, Nairobi pp. 79.

Maingi N., Munyua W. K., Gichohi V. M., Bjorn H., Gathuma J. M. (1998). Resistance to benzimidazole and levamisole in nematodes parasites of sheep in Nyandarua Districts of Kenya, Acta Tropica, 69:31-40.

Ministry of Agriculture, Fisheries and Food, 1986. Manual of veterinary parasitological laboratory techniques, Technical Bulletin No. 18, HMSO, London, 124 pp.

Over H. J., Jansen J., Van Olm P. W. (1992). Distribution and impact of helminth diseases and livestock in developing countries. Food and Agriculture Organization, Rome. pp $30-40$.

Pfukenyi D. M., Mukaratirwa S., Willington A. L., Monrad J. (2007). Epidemiological studies of parasitic gastrointestinal nematodes, cestodes and coccidian infections in cattle in Highveld and lowerveld communally grazing area of Zimbabwe. Onderstepoort J. Vet. Res., 74(2): 129 -42. 
Swai E. S., Mtui P. F., Mbise A. N., Kaaya E., Sanka P., Loomu P M. ( 2006). Prevalence of gastrointestinal parasite infections in Maasai cattle in Ngorongoro District, Tanzania. Vet. Parasitol. 117: 117-120.

The Constitution of Kenya, (2010). Republic of Kenya, Government Printers, Nairobi. First schedule: article 6 (1).

Thrusfield M. (2007). Veterinary epidemiology, third edition. Blackwell publishers, London. pp $267-304$.

Urquhart G. M., Armour J., Duncan J. L., Dunn A. M., Jennings F. W. (1996). Veterinary Parasitology $2^{\text {nd }}$ edition, Blackwell science, pp $4-10$.

Waruiru R. M., Nansen P., Kyvsgaard N. C., Thamsborg S. M., Munyua W. K., Gathuma J. M., Bøgh H. O. (1998). An abattoir survey of gastrointestinal nematode infections in cattle in the central highlands of Kenya. Vet. Res. Commun. 22(5): 325-334.

Waruiru R. M., Thamsborg S. M., Nansen P. Kyvsgaard, N. C., Bogh H. O., Munyua W. K., Gathuma J. M. (2000). The prevalence and intensity of helminth and coccidia in dairy cattle in Central Kenya. Vet. Res. Commun. 24: 39-53.

Waruiru R. M., Thamsborg S. M., Nansen P. Kyvsgaard, N. C., Bogh H. O., Munyua W. K., Gathuma J. M.(2001). The epidemiology of gastrointestinal nematodes of dairy cattle in Central Kenya. Trop. Anim. Hlth. Prod. 33: 173-187. 